\title{
Management of chronic
}

cancer pain: A guideline for client - family teaching

\section{by Stella Dyck and Nancy Guebert}

The oncology nurse is constantly challenged to prepare the client and family for self-care in the home following active treatment, and, intermittently during the palliative phase of the cancer experience. Nurses are increasingly cognizant of the need to teach clients and families self-care. Numerous teaching aids are available to assist the nurse in carrying out teaching in relation to symptom management following either chemotherapy or radiation therapy. Aids for teaching pain management are less accessible. However, it is the challenge of controlling chronic pain in the home setting that frequently immobilizes the family and necessitates hospitalization of the client (Dobratz, 1990; Ferrell \& Schneider, 1988; Spross, McQuire \& Schmitt, 1990a; Walsh \& Kingston, 1988). The outline in this paper addresses the staff nurses' need for a comprehensive and succinct outline to use in planning the essential teaching to facilitate effective self-care for the client experiencing chronic malignant pain.

Chronic pain has been defined as a subjective experience of discomfort that may occur constantly or intermittently, continues for a

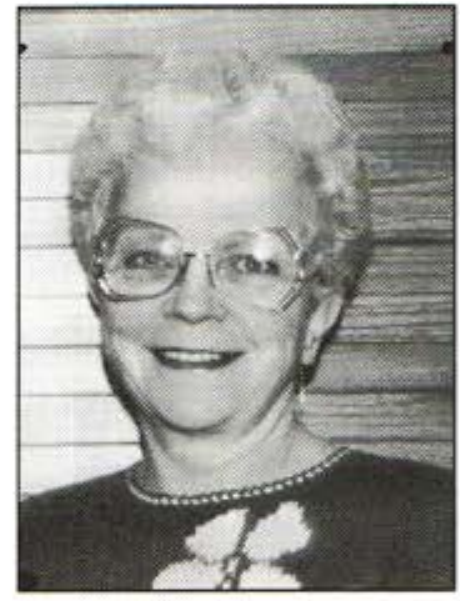

Stella Dyck

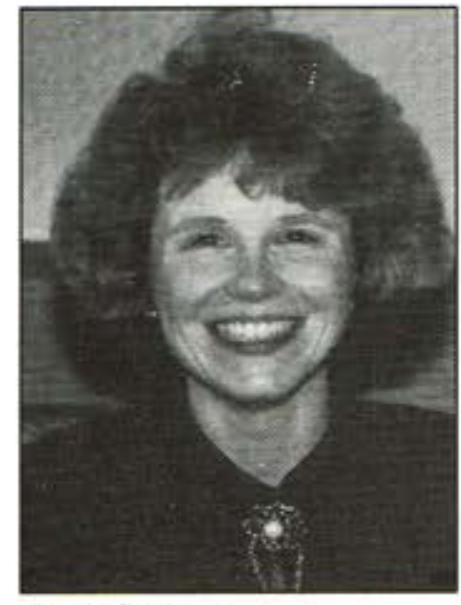

Nancy Guebert period longer than six months, is what the client describes it to be, and exists when the client says it does (McCaffery \& Beebe, 1989; Ziga \& Yasko, 1983). Pain is the most common symptom of cancer, particularly of advanced cancer (Twycross, 1984). The incidence of pain in all clients diagnosed with cancer ranges from $30 \%$ to $71 \%$ (Health \& Welfare Canada, 1984a; Donovan \& Dillon, 1990) and in the terminal phase affects up to $80 \%$ of the clients (McKegney, Bailey \& Yates, 1981). There is reported disregard for client pain by nurses as evidenced by failure to discuss the pain with the client $(57 \%)$, failure to incorporate the problem of pain in the client care plan $(72 \%)$, and failure to document the symptom with related interventions in the progress notes (73\%) (Donovan \& Dillon, 1990). There is some evidence that clients in the home setting experience less effective pain management than in the hospital setting (Ferrell \& Schneider, 1988). Increasingly, nurses are becoming aware of their need to become more knowledgeable about, and develop more effective means of pain management (Bramwell, 1989; Funkhouser \& Grant, 1989; McCaffery, Ferrell, O’Neil-Page, Lester \& Ferrell, 1990; Hockley, 1989; Western Consortium for Cancer Nursing Research, 1987). The Canadian Association of Nurses in Oncology (CANO) considered pain to be such a significant problem that the first position paper to be developed by the association addressed the management of malignant pain (CANO, 1988).

An essential aspect, endorsed by the CANO position paper, in dealing with the problem of pain management in the home and hospital is the involvement of the client and family in the plan of care (McCaffery \& Beebe, 1989; Spross et al., 1990a; Walker, Akinsanya, Davis \& Marcer, 1989). Joint planning of this type requires knowledgeable participants (Walker, et al., 1989). Knowledge provides a means of achieving control in a very stressful situation where loss of control is one of the critical concerns expressed by clients (Austin, Cody, Eyres, Hefferin \& Krasnow, 1986; Walker, et al, 1989). Therefore, client and family teaching becomes one of the crucial requisites of nursing care (Coyle et al., 1985; Dobratz, 1990; Spross et al., 1990a). The Expert Advisory Committee on management of chronic cancer pain recommended teaching packages be developed to increase the general public awareness of the right to relief from cancer pain and resources available for the control of cancer pain (Health and Welfare Canada, 1984b).

The structure for the teaching guideline was adapted from the conventional format of objectives, content identification, teaching

continued on page 8 ...

LA GESTION DE LA DOULEUR CHRONIQUE CAUSÉE PAR LE CANCER: UN GUIDE POUR L'ÉDUCATION DU CLIENT ET DE SA FAMILLE

\section{ABRÉGÉ}

Au Canada, les soins a domicile sont de plus en plus populaires dans le cas de stades avancés du cancer. Ce type de soins exage souvent la gestion de protocoles de contrôle de la douleur des plus complexes. Il est impératif que les clients et leurs familles comprennent les différents aspects d'une gestion efficace de la douleur, y compris la gestion des effets secondaires de certains analgésiques. Les infirmières ont besoin d'avoir un guide d'enseignement complet pour pouvoir s'acquitter de l'éducation des clients et de leurs familles dans ce domaine. Cet article présente le plan de coturs qui permet d'améliorer les soins autonomes des clients atteints de douleur maligne chronique.

Stella Dyck, RN, BScN, M.Cont.Ed., is an Associate Professor at the College of Nursing of the University of Saskatchewan, Saskatoon, SK, Canada. Nancy Guebert, RN, BSN, was a Nurse Educator at the University Hospital, Saskatoon, SK, Canada at the time this teaching plan was developed and is currently Nurse Unit Manager, Palliative Care at St. Paul's Hospital, Saskatoon, SK, Canada. 
the first draft was developed by the authors ${ }^{1}$. This draft was circulated to the Nurse Unit Manager, Nurse Unit Coordinator, and to the Medical Director of the Pain Clinic. After receiving their critique, the teaching guide was revised and prepared for final printing. In-service sessions were held to help nurses use the guideline effectively. It was then made available in a ring binder on the nursing unit; $a$ form that was versatile and accessible for all nursing staff.

\section{Summary}

This guideline has proven beneficial in directing nurses' teaching actions with clients and families. It provides a framework for nurses to assess client issues and to identify problems or needs relating to managing the client with malignant pain. It enables nurses to quickly and effectively identify the most pertinent issues that are interfering with the assumption of responsibility for pain management by the client and family. Although the use of this guideline has not been systematically evaluated, the routine chart audits indicate that the patient education score had risen from a mean of $82 \%$ prior to the introduction of three teaching packages ${ }^{2}$ on the oncology ward to $90 \%$ following their introduction. In this same period family involvement had risen from $58 \%$ to $67 \%$. In our clinical practice family members express appreciation for thorough teaching in pain management.

References follow teaching plan, page 12.
The process of developing the guideline involved months of collaborative
work. Following discussion with key participants in the health care team,

1. One author was a nurse educator employed by the agency and the other author was a university professor responsible for the nursing students' clinical experience on the oncology ward.

2. This package on teaching chronic cancer pain management was introduced at approximately the same time as two other teaching packages. One was on managing side effects of chemotherapy and the other on managing side effects of radiation therapy.

\section{Chronic cancer pain management teaching plan}

Prior to initiating any teaching the client is to be assessed for learning needs and readiness. Only the selected portions of this outline will be relevant to a specific client based on the client's disease status, treatment protocols, educational level, cultural background and personal preference styles for information seeking. Since the client in chronic pain is often terminally ill and unable to expend significant time and energy on learning, the teaching approach will need to be individually adapted. The client's family often has a greater need to learn specifics about pain management than the client. The family's need to learn is particularly important since it is these caregivers who will have to assume responsibility for the pain management in the home setting.

\section{Objective}

\section{Nature Of Pain}

1. Client will be able to describe the pain in relation to location, intensity, quality, duration and trigger factors.

\section{Client/family will be} able to identify how the pain is affecting function and mood.

3. Client/family will be able to identify how other factors may affect the perception of pain.

\section{Content}

-parameters of pain include location, intensity, quality, duration and trigger factors

-pain has different effects on different people -may cause nausea, vomiting, diarrhea, constipation, anorexia

-may cause dizziness, drowsiness, inability to sleep

-may cause depression, crying, irritability, suicidal

thoughts, fear

-may interfere with essential work, self-care activities,

and rewarding personal relationships.

-anxiety and depression may accentuate pain

-muscle tension may accentuate pain

-nausea, vomiting, coughing, movement may accentuate the pain

-treating other symptoms may alleviate pain

-social concerns, financial worries, loss of job, role

changes may all influence the perception of pain.

\section{Teaching} approach

-use body diagrams for pain location -use scales $(1-10)$ to describe intensity

-nondirective

interviewing to assess client concerns about pain -reassurance re the normalcy of typical responses

-one-to-one discussion -exploration of related personal factors

\section{Evaluation of teaching}

-client* verbalizes parameters of pain description

-client keeps record of own pain in daily log or diary

-client verbalizes fears and attitudes concerning pain

-client verbalizes effect of pain on quality of life

-client identifies other factors that may be contributing to the pain or altering the perception of pain -client keeps pain diary to identify factors related to pain experience "hereafter "client" refers to both patient and family 


\section{Chronic cancer pain management teaching plan - page two}

\section{Objective \\ II. AIternate Pain Interventions \\ 1. Client/family will be able to identify and use self-help methods that alleviate pain.}

\section{Analgesics}

2. Client/family will be able to differentiate between narcotic and non-narcotic analgesics.

3. Client/family will be able to explain guidelines for effective use of analgesics to relieve pain.

\section{Content}

-progressive muscle relaxation

-mental imagery

-distraction, music

-heat or cold application

-massage

-TENS

-reinforce client's right to pain alleviation

-additional medical treatment may include surgery,

radiation, chemotherapy, nerve blocks

-discuss relative risks and benefits of possible options

-two types -non-narcotic pain relievers -narcotic pain relievers

-non-narcotic e.g. acetaminophen plus

non-steroid-anti-inflammatory drugs (NSAID)

-non-narcotic drugs do not usually have to be increased

to relieve the same amount of pain over a period of time

-client does not develop a tolerance to non-narcotic

medications

-when person stops taking the non-narcotic pain reliever

there are no withdrawal symptoms

- usually do not cause drowsiness, constipation

-salicylates and acetaminophen give approximately equal pain relief

-both will also reduce fever

- either can be bought without a prescription

-salicylates may cause stomach upset, stomach bleeding and lengthen bleeding time

-acetaminophen does not usually have these side effects -clients with cancer are usually advised not to take

salicylates because of the increased potential for bleeding

-concurrent use of NSAID and narcotics is justified

because of different sites of action

-narcotic drugs may have to be increased over time to

relieve the same amount of pain as the body adapts to

the drug (not necessarily always)

-amount of certain narcotics (e.g. morphine) is virtually

unlimited provided the increase is gradual and in

response to client need for pain relief

-withdrawal symptoms not a problem with narcotics if

dosage reduced gradually

-differentiate between:

-tolerance - after repeated use a given dosage begins to

lose effectiveness

-addiction - overwhelming obsession with obtaining

and using drug for its psychic properties

-dependency - after repeated use withdrawal

symptoms occur when discontinued abruptly based on

physiological changes

-taking analgesics at regular intervals rather than prn is

more effective and dosage requirement is often reduced

-do not try to "hang in there" and wait as long as possible

before taking analgesic

-more analgesic required when pain present and severe

than when taking prophylactically

-if pain relief can be achieved with non-narcotic

analgesics do not take narcotics

-Tylenol and aspirin are stronger analgesics than most people realize

\section{Teaching Approach \\ -use of relaxation tapes teach relaxation \\ technique \\ -give client "Pain Relief" \\ - Canadian Cancer \\ Society}

-discussion with client -give client "Pain Relief" booklet - as above

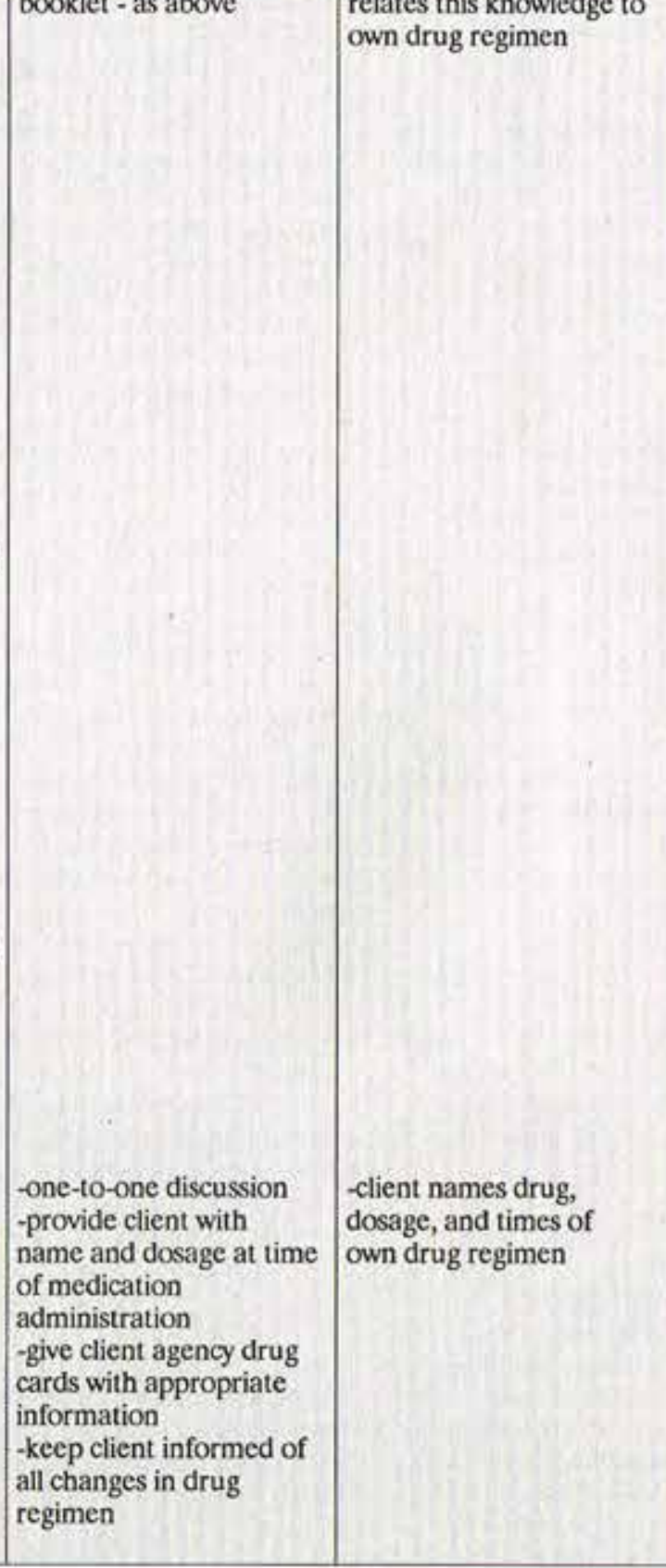

\section{Evaluation of Teaching}

-client demonstrates selected techniques

-client discusses rationale for use of alternate techniques

-client differentiates between drugs and relates this knowledge to own drug regimen 


\section{Chronic cancer pain management teaching plan - page three}

\section{Objective \\ Content \\ -if pain requires narcotic and doctor also orders non-narcotic it is logical and effective to take both because they act at different sites in the body to relieve the pain \\ -the best route to take analgesies is by mouth but many analgesics are also available by suppository, injection, subcutaneous, or intravenous routes if oral route is not tolerated}

III. Efrects or

Analgesics On

Gastrointestinal System

1. Client/family will be able to explain how analgesics may affect the digestive system.

\section{Client/family will be} able to state self-care measures that may alleviate dry mouth syndrome.

-possible side effects of narcotics include dry mouth, nausea and vomiting, constipation

-probable side effect of salicylates and NSAIDs are gastric irritation, nausea, gastric ulceration -possible side effect of acetaminophen is tiver dysfunction

-frequent mouth rinse with normal saline, water or baking soda in water -suck on hard sugar-free candy - eat chunks of cantaloupe or pineapple -avoid mouthrinse containing alcohol
3. Client/family will be able to state self-care measures that may alleviate nausea and vomiting.

4. Client/family will be able to state self-care measures that may prevent constipation.

5. Client/family will be able to state self-care measures that may alleviate gastric irritation.

\section{Effects of}

Analgesics On Central Nervous System 1. Client/family will be able to explain how narcotics may affect the central nervous system. -use lip balm -if radiation has caused dry mouth, artificial saliva may help -maintain oral fluid intake -avoid alcohol, coffec, tea and smoking

-take antiemetic either half-hour before analgesic or at same time with analgesic - may experiment to find best approach

-if nausea is aggravated by movement it may be due to effect of narcotic on ears and may be relieved by lying down

-Scopolamine patch may be helpful for this type of nausea -constipation -take stool softener and stimulating laxative, e.g. ducosate and senna on a regular basis -drink plenty of fluids, aim for $2000 \mathrm{ml}$ per day -add fiber and prune juice to diet -exercise if possible - use commode or regular toilet for bowel movements if possible

-use enemas or suppositories before client becomes uncomfortable due to constipation

- gastric irritation -take medication after meals or with glass of milk

-take 1-2 teaspoons antacid such as aluminum hydroxide, with the medication to prevent irritation

-medications available to suppress gastric secretions, e.g. cimetidine

-medications available to protect mucosal ulcerations, e.g. sucralfate

-initial drowsiness usually clears in 3-5 days on a constant dose -when pain relief is achieved after prolonged pain experience client may have to "catch up" on lost sleep -if drowsiness persists refer to physician for exploration
Teaching
Approach

-encourage client questions

-discuss with client -give client "Pain Relief" booklet

-discussion with client -give client booklet on mouth-care -client performs initial self-care under supervision

discuss with client -give client booklet re nausea, anorexia

discuss with client

-discuss with client

-explain to family -encourage questions
Evaluation of Teaching

client verbalizes understanding of common side effects of current drug regimen

client demonstrates appropriate mouth care measures

-client verbalizes knowledge about interventions

-client verbalizes knowledge about interventions -client makes appropriate food choices

-client verbalizes knowledge about interventions -client takes medications with meals or milk

client verbalizes understanding 


\section{Chronic cancer pain management teaching plan - page four}

\section{Objective \\ 2. Client/family will be able to state self-care \\ Content \\ of other causes or use of alternate analgesics or dose reduction -other side effects may be light-headedness, dizziness, clouded sensorium, euphoria, nightmares (with long-acting morphine), and muscle twitching with large doses of morphine \\ -avoid activities that require alertness (e.g. driving a car) -use of protective devises when ambulating} measures that will prevent injury due to side effects of medication.

\section{Psychosocial} Dimensions of Pain Management

1. Client/family will be able to discuss common misconceptions about chronic pain and use of analgesics.

\section{Client/family will be} able to discuss personal feelings or concern about use of narcotics.

3. Client/family will be able to identify when and how to access additional resources for pain management.

-common misconceptions are: -pain always results in changes in vital signs

-narcotic use always results in addiction

-narcotics depress respirations and may hasten death to achieve pain-free state the client cannot remain alert -lack of expression of pain means client is not experiencing any pain

-pain must have an identifiable cause before use of analgesics is warranted

-nurses and doctors are the experts about degree of pain the client is experiencing

-admitting pain is a sign of a weak constitution

-if narcotics are taken "too early" there will be nothing

available when the pain becomes severe

-drug addiction and drug tolerance are the same

-sociocultural background influences attitudes toward narcotic use

-past experiences (personal, family or friends) influences attitudes toward narcotic use

-religious beliefs influence attitudes toward narcotic use -lack of knowledge may cause fear of addiction, respiratory arrest

-significant others may be opposed to narcotic use -fear of decreased mental alertness may prevent client from using narcotics

-relationship between members of health care team and various agencies involved in care in the community -provide hope that pain can be relieved through use of additional measures and other drug combinations -reinforce client's right to pain relief and need to seek help when pain becomes problematic

\section{Teaching Approach}

-explain to family

-explore client perception concerning myths about pain and analgesics -provide written material about analgesics -provide booklet "Pain Relieft

-explore client attitudes toward narcotic use through open-ended and leading questions -encourage expression of doubts and apprehensions -give factual information about narcotics -advocate for client to make informed decision about balance between pain relief and freedom from analgesic side effects

-provide brochures of relevant agencies in community -follow up with telephone contact Evaluation of
Teaching

-family verbalizes knowledge of necessary precautions

-client discusses difference between common myths and scientific fact relative to these myths

-client discusses feelings, attitudes and past experiences with analgesic use and the effect this has on current response to treatment

-client lists courses of action to be taken if pain becomes a problem again 


\section{References}

1. Austin, C., Cody, C.P., Eyres, P.J., Hefferin, E.A. \& Krasnow, R.W. (1986). Hospice home care pain management: Four critical variables. Cancer Nursing, 9, 58-65.

2. Bramwell, L. (1989). Cancer nursing - a problem-finding survey. Cancer Nursing, 12, 320-328.

3. Canadian Association of Nurses in Oncology (CANO). (1988).

Position statement regarding pain management. CANO.

4. Canadian Cancer Society. (1987). Pain relief: Information for people with cancer and their families. Ottawa, Can: Health and Welfare Canada.

5. Clark, J., Landis, L. \& McGee R. (1987). Nursing management of outcomes of disease, psychological response, treatment, and complications. In C.R. Ziegfeld (Ed.), Core curriculum for oncology nursing. (pp 271-319). Philadelphia, PA: W.B. Saunders Co.

6. Coyle, N., Monzillo, E., Loscalzo, M., Farkas, C., Massie, M.J. \& Foley, K.M. (1985). A model of continuity of care for cancer patients with pain and neuro-oncologic complications. Cancer Nursing, 8, 111-119.

7. Dalton, J.A. (1989). Nurses' perceptions of their pain assessment skills, pain management practices, and attitudes toward pain.

Oncology Nursing Forum, 16, 225-231.

8. Dobratz, M.C. (1990). Hospice nursing: Present perspectives and future directives. Cancer Nursing, 13, 116-122.

9. Donovan, M.I., \& Dillon, P. (1990). Incidence and characteristics of pain in a sample of hospitalized cancer patients. In C. Reed Ash \& J.F. Jenkins (Eds.), Enhancing the role of cancer nursing. (pp 143-160). New York: Raven Press, Ltd.

10. Ferrell, B.R. \& Schneider, C. (1988). Experience and

management of cancer pain at home. Cancer Nursing, 11, 84-90.

11. Ferrell, B., Wisom, C., Wenzl, C. \& Brown, J. (1989). Effects of controlled-released morphine on quality of life for cancer pain.

Oncology Nursing Forum, 16, 521-526.

12. Funkhouser, S.W. \& Grant, M.M. (1988). 1988 ONS survey of research priorities. Oncology Nursing Forum, 16, 413-416.

13. Health and Welfare Canada. Cancer pain: A monograph on the management of cancer pain. Ottawa, Can: Minister of Supply and Services Canada, 1984.

14. Health and Welfare Canada. (1984) Cancer pain: Report of the expert committee on the management of severe chronic pain in cancer patients. Ottawa, Canada: Minister of Supply and Services. 15. Henderson General Hospital. (1983). Control of Cancer Pain. Hamilton, Ont., Can: Henderson General Hospital.
16. Hockley, J. (1989). Caring for the dying in acute hospitals. Nursing Times, 85(39), 47-50.

17. Karb, V.B., Queener, S.F. \& Freeman, J.B. (1989). Handbook of drugs for nursing practice. St. Louis: C.V. Mosby Company.

18. McCaffery, M. \& Beebe, A. (1989). Pain: A clinical manual for nursing practice. St. Louis: C.V. Mosby Company.

19. McCaffery, M., Ferrell, B., O'Neil-Page, E., Lester, M. \& Ferrell, B. (1990). Nurses' knowledge of opioid analgesic drugs and psychological dependence. Cancer Nursing, 13, 21-27.

20. McKegney, P.F., Bailey, L.R. \& Yates, J.W. (1981). Prediction and management of pain in patients with advanced cancer. General Hospital Psychiatry, 3, 95-101.

21. National Cancer Institute. (1983). Questions and answers about pain control. New York, N.Y.: American Cancer Society, Inc.

22. Rankin, S.H. \& Stallings, K.D. (1990). Patient education (2nd ed.). Philadelphia: J.B. Lippincott Company.

23. Redman, B.K. (1988). The process of patient education (6th ed.). St. Louis: C.V. Mosby Company.

24. Skidmore-Roth, L. (1990). Mosby's 1990 nursing drug reference. St. Louis: C.V. Mosby Company.

25. Spross, J.A., McQuire, D.B. \& Schmitt, R.M. (1990a). Oncology Nursing Society position paper on cancer pain: Part I. Oncology Nursing Forum, 17, 595-614.

26. Spross, J.A., McQuire, D.B. \& Schmitt, R.M. (1990b). Oncology Nursing Society position paper on cancer pain: Part II. Oncology Nursing Forum, 17, 751-760.

27. Twycross, R.G. (1984). Incidence of pain. Clinical Oncology, 3 , 5-15.

28. Walker, J.M., Akinsanya, J.A., Davis, B.D. \& Marcer, D. (1989). The nursing management of pain in the community: A theoretical framework. Journal of Advanced Nursing, 14, 240-247.

29. Walsh, S. \& Kingston, R.D. (1988). The use of hospital beds for terminally ill cancer patients. European Journal of Surgical Oncology, 14, 367-370.

30. Western Consortium for Cancer Nursing Research. (1987)

Priorities for cancer nursing research: A Canadian replication. Cancer Nursing, 10, 319-326.

31. Wilkie, DJ. (1990). Cancer pain management: State-of-the-art nursing care. Nursing Clinics of North America, 25, 331-343.

32. Ziga, S.E. \& Yasko, J.M. (1983). Chronic pain. In J.M. Yasko (Ed.), Guidelines for cancer care: Symptom management. (pp 73-93). Reston, Virginia: Reston Publishing Co. Inc.

\section{- W A N T E D! -}

Energetic and enthusiastic nurses to author manuscripts, book and A/V reviews, practice tips and letters to the editor for CONJ.

No previous experience required.

Act today for this rewarding lifetime offer.

Personal satisfaction guaranteed!

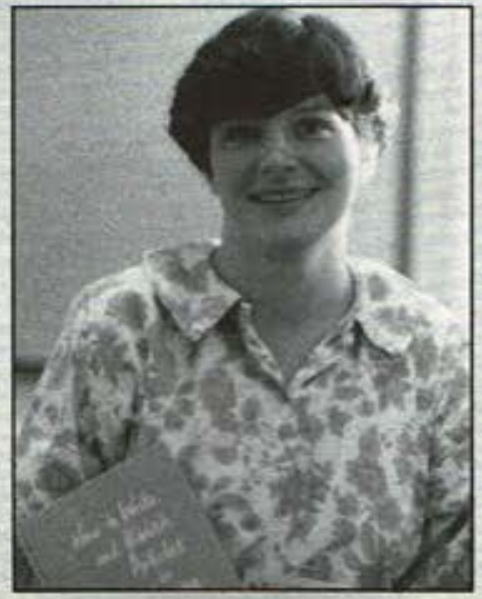

